\title{
A Relational Sociological Analysis on the Impact of COVID-19 Pandemic Lockdown on Syrian Migrants' Lives in Turkey: The Case of Mersin Province
}

\author{
Zeynep Tekin Babuç ${ }^{1}$
}

Accepted: 5 October 2021 / Published online: 12 October 2021

(c) The Author(s), under exclusive licence to Springer Nature B.V. 2021

\begin{abstract}
The COVID-19 pandemic which expeditiously turned into a global health crisis also triggered many risks and uncertainties especially for vulnerable groups such as migrants and refugees as a result of the measures restricting social, economic, and educational life as well as mobility. According to the relational sociological perspective, each uncertainty process creates various changes on social networks and relationships, and these relational changes also affect identities, roles, and relational strategies. With this study, it is aimed to explore the economic, social, and familial impacts of the COVID-19 lockdown on Syrian migrants' lives in Turkey from a relational sociological perspective. The data in the study is obtained by semi-structured qualitative interviews with 13 Syrian citizens living in Mersin province of Turkey. According to the findings of the study, the suspension or slowdown of economic activities due to the pandemic has caused not only an uncertainty about the future, but also a change in familial positions and roles. Also the accepted norms of social relations have been inevitably suspended resulting in increased ambiguity. Strengthening the network of solidarity within relatives and building stronger relationships within the family are common relational strategies of the participants to mitigate the social and economic impacts of the COVID-19 outbreak, but these strategies will not be adequate if the lockdown process is prolonged. Considering the fact that the lockdown measures can be tightened again at any time, social and economic policies should be expanded to include the Syrian migrants in Turkey.
\end{abstract}

Keywords The COVID-19 pandemic $\cdot$ Lockdown $\cdot$ Syrian migrants $\cdot$ Relational sociology

Zeynep Tekin Babuç

zeyneptekinbabuc@gmail.com

1 Department of Social Work, Osmaniye Korkut Ata University, Osmaniye, Turkey 


\section{Introduction}

The COVID-19 pandemic which is caused by the infectious coronavirus SARSCoV-2 disease (COVID-19) resulted in a global health crisis. The outbreak of this newly discovered coronavirus was first identified in Wuhan, Hubei, China in December 2019, and was declared a pandemic by the World Health Organization (WHO) on 11 March 2020 (Relief International, 2020). Due to the exponential spread of the disease worldwide, countries have had to take measures restricting social, economic, and educational life as well as mobility to mitigate the outbreak and control the emergency situation. In Turkey, the first case was reported on 11 March 2020 and the Turkish government took a host of measures to reduce the spreading of the disease including flight bans, closing of schools, suggesting self-isolation, reducing mobility of people over 60 years and under 20 years of age, closing non-essential shops, restaurants, cafes, and other service sector institutions, and reducing hours of supermarkets with staggered entrances (Relief International, 2020).

Decrease in direct social contact and physical and social isolation may result in an increase of emotional distress and mental health problems. Nevertheless, the impact of the COVID-19 pandemic is not limited to emotional distress and sense of loss that result from reduced direct social contact. Individuals also experience possible multiple forms of loss such as loss of a loved one, educational opportunities, employment, recreation, freedoms, and social support (Holmes et al., 2020). Sudden loss of income and restrictive quarantine measures may trigger existing or new mental health problems. Experiencing financial loss during the pandemic, frequently following COVID-related news and posts in media, and spending longer time at home during the pandemic were found to be associated with higher post-traumatic stress sypmtoms (Ikizer et al., 2021).

The mitigative measures taken to control the spread of the disease affect all people, but all of us do not suffer equally from this life-changing crisis. Although the COVID-19 pandemic has lead to a global health crisis, disadvantaged groups are affected more from its health, social, and economic consequences. Women, poor, homeless, elderly, disabled people, and migrants can be regarded as at higher risk than the other segments of the population (Kara, 2020). Due to insufficient financial resources and inability to access healthcare or health insurance, migrants are hardly likely to take the necessary precautions against COVID-19 or to receive the required medical care in case they are contaminated (McAuliffe \& Bauloz, 2020). Also the restrictive measures on economic activities hit the migrant population who mostly work in informal sectors with unsecured and poor conditions in the labor market. Many working migrants lost their jobs and incomes without a system of social and economic protection that can help them to survive during the pandemic. Being a marginalized section of the society who are mostly dependent on daily wages for their living, migrant workers are found to experience an increase in negative emotions and feelings such as loneliness, tension, frustration, low mood, irritability, fear, fear of death, and social isolation due to the lockdown process (Kumar et al., 2020).

Migrants' vulnerability to direct and indirect economic, social, and psychological impacts of COVID-19 can be affected by a variety of factors including their 
living and working conditions, lack of consideration of their cultural and linguistic diversity in service provision, xenophobia, their limited local knowledge and networks, their access to rights, and level of inclusion in host communities (Guadagno, 2020; Liem et al., 2020). These vulnerability factors are not specific to migrants and may also be shared with other poor and marginalized citizens of the host community, but migrants often encounter unique sets of challenges associated with access to healthcare, exclusion from welfare programs, and fear of stigmatization and/or arrest and deportation due to their migrant status (Guadagno, 2020). In terms of the long-term goals on migrants' integration and social cohesion, uncertainty and anxiety environment triggered by COVID-19 may cause the increase of feelings of distrust and instances of discrimination against migrants induced by fake news, misinformation, and politicization of the issue (McAuliffe \& Bauloz, 2020). Considering that restriction of human mobility is a prior measure taken by most of the countries in pandemia period, migrants can also be regarded as a risk for contagion of COVID-19, which may result in increased discrimination and exclusion of migrants.

As being the leading country in hosting over 3.5 million Syrian migrants of approximately six million Syrians who had to migrate out from Syria to nearby countries because of the civil war (UNHCR, 2018), Turkey has already been under pressure of managing this migration flow and social integration challenges of Syrian migrants, the majority of whom are expected to stay permanently in Turkey. The COVID-19 pandemic has increased this pressure and brought new challenges that the Turkish government and Syrian migrants in Turkey have to encounter. The Turkish government did not bring out seperate statistics of the migrant population in Turkey who were contaminated with COVID-19, but it is known that most Syrians live in crowded households in urban settings with higher risks of infection and the pandemic made it harder for them to meet their basic needs and access to livelihood opportunities (Kirişçi \& Yavcan, 2020b). A vast majority of Syrians in Turkey reside in towns and cities across almost the whole country, with only less than $2 \%$ living in camps and most of them are under the status of "temporary protection" and have access to a range of free public services, including education and healthcare (Kirişçi \& Erdoğan, 2020a). Considering that, apart from a few Syrian business owners, most of the Syrians in Turkey are unskilled workers who work in the service sector or manufacturing industry, and they are highly affected from the virus lockdowns (Kazanc1, 2020). These unskilled Syrian workforce mostly work in informal sectors and they mandatorily quit working without any financial support or have to continue to work in unsafe conditions with a high risk of contamination during the lockdowns. The Turkish government provides financial support for Turkish citizens to mitigate the economic impacts of COVID-19 outbreak, but this aid is not accessible to Syrian migrants who are under temporary protection (Turkish Red Crescent, 2020).

A study conducted by the Association for Solidarity with Asylum Seekers and Migrants (ASAM) (2021) states that while some Syrian migrants receive small-scale financial aid through public institutions, local authorities, NGOs, and UN agencies, most of them try to manage the economic challenges caused by the pandemic by borrowing money, spending savings, selling household assets, and buying food 
on credit. Due to job losses in the pandemic, these humanitarian aids become the main sources of livelihoods for the refugees in Turkey. While Afghans rely more on humanitarian support and Iraqis rely more on community support, Syrians in Turkey rely more on their personal belongings (ASAM, 2021). Considering the fact that surviving with small-scaled financial aids, community support, or personal savings is not easy and sustainable in the long run, some of them have to continue to work against restrictive measures, taking the risk of becoming sick due to the COVID-19 virus.

A need assessment study on the effects of COVID-19 outbreak on Syrian refugees in Turkey shows that the outbreak appears to affect multi-sided aspects of Syrian refugees' lives as $87 \%$ reported someone in their household lost their job because of the outbreak, $71 \%$ reported that they cannot access health services, and $81 \%$ reported that they have unmet urgent needs such as food and hygiene material (Relief International, 2020). Another study points out that $63 \%$ of Syrian participants living in Turkey have encountered difficulties in reaching food and $53 \%$ of those have difficulties in meeting hygiene conditions, $48 \%$ of the respondents reported problems in accessing online education, and $65 \%$ of them have problems paying their rent or utility bills during COVID-19 outbreak (ASAM, 2020). Although the Syrians under temporary protection in Turkey can use healthcare services free of charge, unregistered Syrians who form around $10 \%$ of the Syrian population in Turkey still experience challenges in accessing healthcare and they are at higher risk in case of contact with the disease (Kazanc1, 2020).

In terms of educational challenges that migrant children and their families experience during COVID-19 outbreak, the measures put in place by the Turkish government like closing schools and launching online learning have not taken into account the particular needs of refugee children (Kollender \& Nimer, 2020). Since the launch of online education, Syrian students are one of the major refugee groups in Turkey who have challenges attending online classes. The highest rates of children not attending online education were among Afghan and Syrian students respectively and the main barriers to access remote education were absence of internet connection, lack of equipment, language barriers, absence of TV, and TV connection (ASAM, 2021). Although a particular measure for Syrian migrant children has been taken by adding specific Turkish language programs to the television channel of Eğitim Bilişim A $\breve{g}_{1}$ (EBA), which is the name of the online distance learning program in Turkey, there has not been a financial or technological support given to migrant families during this period (Kollender \& Nimer, 2020). Given the fact that more than half of the Syrians in Turkey are under the age of 24 (Directorate General of Migration Management, 2021), further measures that focus on the specific educational, financial, and technological needs of Syrian migrants in all levels of education should be considered in planning processes. Otherwise, the closure of schools across the country and continuation of education via distance learning may affect the Syrian population negatively and also hinder the educational policy of Turkey to integrate Syrian children into the Turkish education system (Kazanc1, 2020).

These studies point out the fact that the COVID-19 pandemic has been worsening the conditions of the Syrian population in Turkey to the extent that they have to struggle even to meet their basic needs. Even though they had various challenges 
prior to the pandemic, this global health crisis may have doubled these problems and also triggered many risks and uncertainties in many aspects of their lives. Consequently, they have to develop new strategies and maneuvers to protect their own security and increase their chance of survival during the pandemic. According to the relational sociological perspective, each uncertainty process creates various changes on social networks and relationships, and these relational changes also affect identities, roles, and relational strategies.

Relational sociology approach brings a new perspective to the concept of agency and it has been effective in migration and refugee studies. According to the relational sociological perspective, social construction is relational as its nature and relational approach tries to overcome the conflict between structure and agency focusing on the dynamic interaction between them in different social environments (Mische, 2011, p. 81) In this theoretical viewpoint, agency is not a feature of the actor, but it is a result of actor's activities, his/her available resources, alliances, and networks and it is a structural component of any social status (Köngeter \& Smith, 2014). Relational sociological viewpoint regards a social relation as a trans-action and defines relations as transactions unfolding within social networks (Emirbayer \& Mische, 1998). Social relations derive their meaning and identity from the changing attributes, behavior, or functional roles they play within that transaction and the dynamic, unfolding process of transaction becomes the primary unit of the analysis (Emirbayer \& Mische, 1998).

According to White (2008) who has made important contributions to relational sociological approach, we are living in a world of contingency and social chaos and we do maneuvers as social actors because we have the ability of creating and breaking social ties. According to him, identity is revealed in a social relationship to maintain control in contingency and uncertainty situations to seek social footing while competing and interacting with other identities, and identities switch between netdoms in their control seeking process to find a safe area without contingency and inconsistency (2008, p. 9). The COVID-19 pandemic has also brought chaos and contingency to the lives of migrants and they have to apply new strategies and maneuvers to maintain control and stability in their lives. In this respect, relational sociology literature provides a convenient viewpoint to interpret the relational impacts of the COVID-19 outbreak on Syrian migrants' lives.

Although the studies widely show that the COVID-19 pandemic has psychosocial, economic, and health consequences on the lives of migrants, which is an expected outcome considering the pre-existing inequalities making migrants vulnerable to handle the negative outcomes of a global health crisis, there is limited research focusing on the relational changes and coping strategies of migrant families during the pandemic. In a study focusing on rural migrant families, members of these families are found out to assist each other in the form of reciprocity and emotional support, and as a result the family can work as a unit to maximize resources and reduce risks during the pandemic (Tang \& $\mathrm{Li}, 2021$ ). Coping mechanisms of marginalized groups such as migrants can be distinct from those adopted by the majority of the population in the way that a household strategy as taking the entire household as a unit can be vital for those who are neglected by the existing welfare system in times of crisis and family may occur as an essential source of support 
to which individuals turn to relieve their suffering (Tang \& Li, 2021). Studies also highlight that disadvantaged people such as migrants have a coping strategy as relying on kinship and social networks based primarily on shared nationality, language, religion, and a sense of collective commitment in times of crisis like disasters and economic difficulties (Hilfinger Messias et al., 2012; Sacchetto \& Vianello, 2015). In line with these findings, studies from Turkey exploring the experiences of Syrian families' during the integration process also show that Syrian families often use social networks based on kinship and nationality to enable their survival in a new country (Tekin Babuç, 2016), and especially child members of these families take an active role to ease the integration process for their families by supporting other siblings, teaching Turkish to their parents, and expanding the family's social networks and interactions (Tekin Babuç, 2018).

Despite these studies revealing that migrants show resilience and adopt specific coping strategies when they encounter crisis such as disasters and socio-economic challenges, further studies are needed to examine the multi-sided changes, challenges, and coping strategies that migrant families experience during the COVID-19 pandemic. As a result, this study aims to contribute to the field by exploring the familial, social, and economical changes experienced by the Syrian families in Turkey and their coping strategies during the COVID-19 outbreak by using a relational sociological viewpoint. Considering the fact that most of the Syrian migrants are highly expected to be permanent in Turkey and are in the process of building and integrating a new identity here, this study will also contribute to the efforts to determine the risk and resilience factors specific to this population and to take mitigative measures accordingly. In line with these purposes of the study, answers to the following questions will be sought:

a) How did the COVID-19 lockdown impact the familial aspects of the Syrian migrants' lives who are under temporary protection in Turkey?

b) How did the COVID-19 lockdown impact the social and economic aspects of the Syrian migrants' lives who are under temporary protection in Turkey?

c) What are the relational strategies and maneuvers they have developed regarding the changes in familial, social, and economic aspects of their lives during the COVID-19 lockdown?

\section{Method of the Study}

This study, in which the relational changes experienced during the COVID-19 pandemic by Syrian migrants settled in Mersin city center in Turkey were explored, was carried out with biographical research methodology. A biographical study is a form of narrative study in which the researcher writes and records the experiences of another person's life (Creswell, 2013, p. 72). Biographical research methods are frequently used in studies on migrants and refugees (Lechner, 2014). The focus is usually the challenges and problems faced by refugees in the process of integration by exploring important events and breaking points of the interviewee's life. In line with this research methodology, semi-structured qualitative interviews were carried 
out with the participants regarding the relational changes in familial, social, and economic aspects of their lives during the COVID-19 lockdown.

The inclusion criteria of the study are determined as being an adult Syrian migrant under temporary protection living in Mersin province of Turkey. In line with this criteria, 13 Syrian citizens (nine female and four male) living in the Akdeniz district of Mersin province participated in the study. All of the participants are under temporary protection in Turkey, have been living in Mersin province for 5-7 years, and aged between 20 and 65 years old. Sample of the study is chosen by using a snowball sampling procedure which is a method of expanding the sample by asking one informant or participant to recommend others for interviewing (Crabtree \& Miller, 1992). In this regard, initially two Syrian migrants who participated in former studies of the researchers are asked for their participation and they refer other Syrian migrants living in Mersin to be included in the study. Most of the participants of the study were living in the Akdeniz region of Mersin province which is a common location preferred by socio-economically disadvantaged Syrian migrants due to relatively low rental fees. A Syrian citizen who is a Bayırbucak Turkmen living in Mersin and speaking both Turkish and Arabic helped in translation. He initially asked the participants for their consent for the study via phone and scheduled a faceto-face visit or a phone interview with the participants based on their preference. Out of 13 participants who accepted to participate in the study, seven were interviewed in their residence by paying attention to social distancing and hygiene rules and six were interviewed via phone call.

Mersin province is chosen for the study as it is home to a large number of Syrian migrants because of its proximity to Syria and because of better living and working conditions in comparison to other cities nearby. According to official figures, there are about 226,000 Syrian migrants living in Mersin province as of March 2021 and the percentage of Syrian population to province population is $12.29 \%$ (Directorate General of Migration Management, 2021).

Language difference between the researcher and the participants is a limiting factor in the study and taking help for translation might have caused some data loss. In face-to-face interviews, it was easier to control this possible data loss by observing the dialog between translator and participants and to clarify possible misunderstandings or unclear points. To minimize this risk of data loss in telephone interviews, Turkish-speaking members of the participating families, if any, were asked for their help to observe the interview process and make explicit in case of a misunderstood or unclear question or answer. The snowball sampling methodology can also be considered a limiting factor in the study. The Syrian refugee population in Turkey is very heterogeneous in the way that they have diversified socio-economic, ethnic, and religious backgrounds. With this respect, while exploring the effects of the COVID19 pandemic on their lives and understanding the resilience, strengths, and coping mechanisms of the Syrian migrants to survive in this global health crisis, snow-ball sampling methodology may limit the representativeness of the sample and may fail to reflect the whole picture of the Syrian migrant population in Turkey. Also the difficulty of composing a common time schedule for interviews with the translator and participants was another limiting factor for the study making it difficult to schedule additional interviews that can be helpful to understand the whole picture better. 
This hardship also made it difficult to interview with a large-sized participant group, limiting the researcher to analyze the findings with respect to age and gender variances. In terms of ethical considerations, an ethics committee approval document was given by Osmaniye Korkut Ata University Scientific Research and Publication Ethics Committee for the study.

In the study, qualitative data was obtained by using a semi-structured open-ended interview form which is prepared by the researcher in line with the aims of the study and the interviews are recorded upon participants' consent via voice recording device. The interviews of the study were carried out in July 2020. All interviews lasted approximately one and a half hours for each participant, and in case of need additional interviews were carried out via phone call. In terms of confidentiality, each participant was coded separately as P1, P2, P3, and etc. The interview transcripts were analyzed by a thematic analysis process using manual coding techniques. Thematic analysis is carried out by following a six-step guide introduced by Braun and Clarke (2006). The first and second steps are realized by being familiarized with the transcribed data and reading the data carefully by trying to combine related patterns of transcripted conversations into codes. Then, these relevant codes are collected under four themes as uncertainties, social, economic, and familial changes. The themes derived from the thematic analysis are grouped and discussed under three titles in relation with the research questions and relational sociological literature.

\section{Findings and Discussion}

The main themes of the thematic analysis are discussed under three titles as "uncertainties and the COVID-19 lockdown," "change of agency in social and economic networks," and "relational changes in the family".

\section{Uncertainties and the COVID-19 Lockdown}

According to the relational sociological viewpoint, contingency is an uncertainty situation that arises from unexpected external influences on the social network (White et al., 2013, p. 140). In case of contingency, identities try to gain control over the unexpected situation by implementing strategies and maneuvers to continue their survival and this can result in emergence of new identities in the process of seeking social footing. The COVID-19 pandemic has become a source of contingency in many aspects because it has brought unexpected influences and uncertainties to individuals' lives.

The suspension and slowdown of economic activities due to the pandemic are among the most important factors that raise uncertainties in everyday life of Syrian migrants. The findings of a survey conducted by the Turkish Red Crescent (2020) confirm that COVID-19 has had a significant economic impact on the refugee population in Turkey especially in terms of major employment losses, challenges to meet basic needs including food and shelter, and access to cash assistance to cover rent 
and bills. In line with the findings of this survey, the participants in our study have also experienced a drastic and unexpected change in the economic condition of their families due to the pandemic, which increases the uncertainties and anxieties in their lives. Almost all of the participants declared that at least one of the working members of their families had to quit work due to the lockdowns, and the daily earnings of the families were significantly decreased.

Syrian families in Turkey mostly live in households with a large population and the number of economically dependent ones is usually higher than the number of breadwinner family members. The breadwinner roles are mostly carried by young male members of the family who can work in physically demanding jobs such as waste collection or construction sectors. In Turkey, among all refugees working in informal and temporary jobs-mostly in textile, construction, and service sectorsSyrians took the lead (ASAM, 2021). These are also the most affected sectors in the pandemic which have mostly suspended work due to governmental measures leaving the unsecured workers jobless for an indefinite period. Similarly, the working members of the participants' families were mostly unskilled workers in the manufacturing and construction industry or waste collectors who experienced a loss in their daily incomes due to the pandemic. While the manufacturing and construction sectors have been suspended due to lockdown measures, the waste collectors also could not make money as before because all the factories and stores that throw away sheet and plastic were closed. The loss of job or income of the breadwinners arised anxieties for all participants, especially the ones who did not have any family member to substitute the breadwinner role. Some of the female participants who experience this economic dependency in their families told about their despair and worries:

P7 (Female, 65): My husband died 13 years ago and I am living with my son, who is 32 years old and with his family. He is the only one bringing home bread. He is a waste collector but he couldn't work during the lockdown.

P1 (Female, 44): My husband died in the war in Syria and I am living with my four children here. My two sons are working in textile manufacturing. They could not work during the outbreak because the factory was closed due to the prohibitions.

For the Syrian participants in our study, the uncertainty about the end date of the pandemic made it hard to struggle with the economic hardship increasing the feelings of anxiety, fear, and hopelessness. The suspension of economic life might have affected all of the family, but not being able to discharge the breadwinner role as before also led to negative feelings for especially the male members of the family. The report of the World Food Programme (WFP) (2020) states that while female migrants' anxieties in the pandemic are more associated with the health risks due to the COVID-19, male migrants experience more socio-economic-related anxieties such as fear of losing jobs. These gender-based differences in terms of the anxietytriggering factors reflect the fact that suspension of the breadwinner position of male family members makes them more prone to psychological risks and problems as they have been usually the ones who carry the economic burden of the family. Some breadwinner participants of the study define this psychological distress and anxiety with these words:

P12 (Male, 35): I am living with my wife and four children aged between 3 to 9 years. I am the only one working in the family and I am a waste collector. 
Normally, I was earning around 50-60 TL everyday by waste collecting but now due to the pandemic if I can earn money for one day, I can't earn enough money for the next two days. I couldn't find any other job because I have a problem on my leg that stops me from doing every job. The lockdown affected us very badly.

P10 (Male, 26): I am living with my wife and my son who is 1,5 years old. I was working as a painter in construction, but I couldn't find any job during the lockdown. For almost the last four months, our economic condition has been very bad. I am very worried about not being able to pay the rent. I don't want to move to another place. We don't have money to afford to move to a new house.

The COVID-19 pandemic has brought a change, in which identities experience failure or limitations to fulfill the needs of their current roles. Also, they have to adopt new strategies to control the risks and uncertainties raised by the pandemic. With regard to the search for control of identities over uncertainties, White (2013, p. 138) identifies the concepts of ambiguity and ambage to explain this process. According to him, ambage refers to uncertainty in social roles and relations and ambiguity refers to uncertainty in social rules and meanings. In case of ambage, status and roles are temporarily suspended and uncertain, but identities are more free to form new strategies to adopt and control the unexpected changes in social environment and to reduce uncertainty and contingency situations (White, 2008). The findings of our study also reflect the increase in ambage and the control efforts of the participants to cope with the given economic challenges and uncertainties. One of our male participants told about how he unwillingly assigned the breadwinner role to his daughter to make the family survive in the pandemic:

P8 (Male, 40): I was working as a dyer in constructions previously, but I couldn't find any job during the lockdown. I have four children and the eldest one is my daughter aged 15. My daughter had to work because of my job loss. She started to work in a textile factory, which was open during the lockdown with a salary of 1000 TL per month.

These economic uncertainties brought about by the COVID-19 pandemic are not unique to the migrants and are experienced by most individuals. A study exploring the outcomes of the pandemic in Turkey states that the limitation of social and economic life due to restrictive measures leads to an increase in ambage as individuals fail and/or avoid the role expectations in the society (Kasapoğlu and Akbal, 2020). But the newly adopted strategies to control this ambage situation may vary due to the unequal socio-economic positions of the individuals. For the disadvantaged segments of the society for whom the meaning of survival in the pandemic is to be able to meet the basic needs, adopting some undesirable survival strategies can be inevitable. For instance, some participants of the study stated that children in the family had to work in jobs not suitable for their ages and in risky conditions because of the economic hardship experienced due to the pandemic:

P1 (Female, 44): It has been very hard for us to keep food on the table during the lockdown. We are spending the money we salted away when the children were working. My youngest son who is 16 years old has started street trading to bring money home.

P11 (Female, 35): I was working in textile manufacturing before the lockdown. My husband has asthma and he couldn't work for years. Because of the lockdown, I 
have to quit working because the manufactory was closed. My 10-years-old daughter and 11-years-old son had to work because of my job loss. They started to do an errand at a local grocery store.

Ambiguity is another relational sociological concept defined as the uncertainty about meanings, values, and rules that arise in the cultural framework (White, 2008). During the COVID-19 outbreak, social rules and meanings that are laid down in society are suspended due to the precautions taken by the administrative identity (Kasapoğlu and Akbal, 2020). This resulted in increased ambiguity especially in the meanings and rules in socio-cultural context in the way that daily routines such as visiting neighbors and relatives, outdoor activities, mass celebrations, ceremonies, or worships were banned due to the lockdown measures. The statements of participants in our study show that these changes in the norms of social relations mostly affected them negatively limiting their social life and preventing them to meet their psychosocial needs:

P1 (Female, 44): I have diabetes and I am staying at home all the time in order not to contract the disease. Before the pandemic, I was visiting neighbours and relatives, but now I didn't even pass out the doorstep. It is not easy, but we have to.

P4 (Female, 40): Before the lockdown, I had good relations with my Turkish neighbours who are from Mardin and know Arabic, but I don't have contact with them now because of the disease. I miss chatting with them.

The social isolation measures and the ban on going out except for reasons of necessity have limited the face to face interactions within social networks. For most of the individuals, these social needs and routines have been mostly replaced by online communication practices. Although continuing these social routines via virtual options has been an effective strategy to decrease the negative outcomes of social distancing, not everyone has the opportunity to use these digital technologies to keep in touch with their social networks. In terms of the Syrian participants of the study, their pre-pandemic social networks were mostly composed of face to face interactions with neighbors and relatives. With increased economic hardship due to the pandemic, allocating money for virtual communication or technological devices such as smartphones is not easy for migrant families who experience difficulties of bringing food to the table. The economic inequalities not only make it hard for the disadvantaged ones to access to the basic needs or health services, but also to have alternative technological strategies to maintain the social dimensions of their lives.

\section{Change of Agency in Social and Economic Networks}

From a relational viewpoint, the physical, economic, and psychosocial problems arised by the COVID-19 pandemic should be evaluated interrelatedly in the way that all of them have a triggering effect on the other aspects of Syrian migrants' lives. Economic problems experienced due to the pandemic or restrictive measures on social life may also trigger psychological problems.

As the majority of the population, Syrian migrants experience physical and social isolation due to the lockdown measures which may constitute a source of emotional distress for all of the family members (Doctors of the World-Turkey, 2020). 
Although it is so-called the new normal and most people are aware of the importance of being attentive to follow the social isolation and hygiene rules, it is not easy to adapt to this sudden isolation from the social networks which are very important for one's social and emotional well-being. Especially the elderly ones, who were subjected to stricter lockdown measures, have experienced this change in agency in social networks more severely. The eldest participant of the study also mentioned about the hardship of being isolated from social networks in these words:

P7 (Female, 65): I am 65 and I am worried about the disease because of my age. I was at home all the time during the lockdown and got bored.

According to the statements of Syrian migrants in our study, despite the difficulty of adapting the decrease in social contacts, they were very careful to follow the social isolation measures and significantly limited their social contact with other people to minimize the contamination risk of COVID-19. The sensitivity and care of the participants to comply with the social isolation measures may derive from the fact that most of the participants have a sick and/or elderly member in the family who are in increased risk of severe COVID-19 disease:

P5 (Female, 35): I am living with my husband and four children. My husband has a heart disease and he can't work. Because of the sickness of my husband, we didn't visit anybody during the lockdown. We even didn't go to the hospital for my husband's medicines because the hospitals are risky.

P8 (Male, 40): My children have asthma and they have to use medicines but we didn't go to hospital in the lockdown not to contract the disease. We stayed at home and didn't visit anybody to protect ourselves.

P4 (Female, 40): We didn't visit anybody during this period and didn't let anybody visit us either because my son has diabetes and it is very risky for him if he contracts the disease.

Despite this significant decrease in social contact, the Syrian migrants participating in our study seem to have an increased agency in terms of forming a network of solidarity within relatives to cope with the economic impacts of the COVID-19 lockdown. From a relational point of view, social actors face everyday challenges to gain control over symbolic, positional, or emotional resources and this requires a change in actor's plans and resources leading to increased levels of agency (Emirbayer \& Mische, 1998). In case of migrants, challenges such as access to livelihood resources, sheltering, and employment opportunities require developing effective and practical strategies and maneuvers which increase their agency and resilience to cope with the contingencies and uncertainties. Staying in touch with relatives and developing social networks with people from their places of origin are common strategies of migrants to increase the likelihood of survival in a new country. Most of the participants of the study have built a stronger network of solidarity as a relational strategy to cope with the economic challenges they face during the lockdown process:

P5 (Female, 35): My two daughters who are aged 14 and 10 are working in textile manufacturing and they are the only ones bringing money home. The factory was not opened for a while due to the lockdown and we got very worried. They found another job in a store where they ran an errand for a little money. But we still have to borrow money from a relative living in İstanbul to buy food and pay the rent. 
P11 (Female, 35): We couldn't afford to pay our rent which is 550 TL per month and we had to borrow money from relatives. We are really struggling to make a living.

Emirbayer and Mische (1998) examine the concept of agency at three levels: iterational (habitual), projective, and practical-evaluative. They define the iterational element as a form of agency in which actors preserve their past patterns of thought and action to sustain stability and order to social universes. The activeness of iterational level leads to the maintenance of previous ties, identities, interactions, and institutions. The projective element is a form of agency that actors are open to "possible future trajectories of action, in which received structures of thought and action may be creatively reconfigured in relation to actors' hopes, fears, and desires for the future" (Emirbayer \& Mische, 1998, p. 971). In the practical-evaluative element, actors use their capacity "to make practical and normative judgments among alternative possible trajectories of action, in response to the emerging demands, dilemmas, and ambiguities of presently evolving situations" (Emirbayer \& Mische, 1998, p. 971).

With the changes and uncertainties raised by the pandemic, maintaining accepted social norms, relations, and strategies has become ineffective and had to be transformed to adapt to the new normal. As a result, actors can perform less in iterational level but much more in practical-evaluative level of agency to take control of the new occurring risks and uncertainties. As for Syrian migrants in our study, they mostly act on the practical-evaluative level by complying with the social isolation measures, adapting to the new social norms, changing their financial strategies, and strengthening the network of solidarity within the family and with their relatives. These coping mechanisms of migrants are effective strategies as they are a marginalized and often neglected population who are often excluded from the welfare and social support system in times of crisis, and relying on family, kinship, and social networks occurs as a social and economic support system to increase the chance of survival (Tang \& Li, 2021).

\section{Relational Changes in the Family}

The social isolation measures have affected interpersonal relations and social routines leading to an increased distance in social relations with relatives, friends, or neighbors but increased agency within the family in terms of spending more time inside the house. Due to the closure of schools and restrictions to use indoor and outdoor parks and activity places, the social and educational needs of the young members of the family have also been completely delegated to the family (Musolino, 2020). The family has become the center of social life and increased family time highlighted the visible strengths and fragilities in familial relationships and led to changes in relational scenarios within everyday family life (Musolino, 2020).

As it is now, before the pandemic, female participants of the study were mostly housewives and out of economic life, but the suspension of economic activities also affected their daily routines. While working members of the family started to spend much more time at home due to closure of work places and lockdown, child 
members of the family also became full-time family members due to the closure of schools. With limited economic and social sources due to the pandemic, managing these increased domestic and care labor has become a considerable stress factor within the family. These changes put pressure on especially the female members of the family who mostly took the responsibility of organizing family life. This organizational burden includes not only the management of domestic and care labor, but also supplying the practical and emotional needs of family members (Rolland, 2020). This domestic inequality already existed before the COVID-19 pandemic, but with increased economic inequality and domestic burden, the disadvantaged position of the women in the family became more visible in the lockdown. Some female participants of the study also mentioned feeling this increased physical and emotional burden at home due to the pandemic:

P3 (Female, 24): We were visiting relatives before, but now we are mostly at home. We only go outside to buy food. My children are small and before I was letting them play outside but now they are mostly at home and they are arguing much more because of being at home all the time.

P4 (Female, 40): I have to do a lot of house work and prepare more meals because the kids spend more time at home. Also I can not cope with the children any more. They are not listening to me when I want them to study their lessons. I turn on the T.V. for them to follow the lessons, but they don't pay attention.

The economic, social, and educational restrictions due to the pandemic result in re-organization of everyday life and change in familial roles and relationships. Families have to cope not only with the stress of social distancing, but also with the decreased social and caregiver support from the extended family. Some families also have to adapt to the changing economic and familial activities such as working from home or job loss and home-schooling. With these increased emotional, economic, and social burden, families often feel enormous stress which can also be associated with increased domestic violence and mental health problems during the COVID-19 pandemic (Fegert et al., 2020). As a result of increased social and economic stressors, evidence shows that social isolation and quarantine measures have raised the problems in familial relations, and the rate of domestic abuse and violence have significantly increased all over the world (Usher et al., 2020).

Before the pandemic, social networks used to serve as a protective factor to reduce family tensions in a way that it allows family members to cope with negative feelings within the family and interpersonal pressures (Musolino, 2020). The pandemic has narrowed this social recreational area and family members have to reshape their relational needs and expectations from each other. This inevitable demand for change in familial relations is much more prevalent in larger and crowded households in which growing of interference and tension is easier because of inadequate privacy opportunities (Lombardo \& Mauceri, 2020). Despite all the negative psychosocial and economic outcomes of the pandemic, this global health crisis may also result in opportunities for family cohesion for some families, especially for the disadvantaged ones such as migrants who have to find support within the family due to their exclusion from social welfare and support systems. Although, similar to the general Syrian profile in Turkey, the participants of the study mostly live as large families including different generations and children of different ages, 
they did not mention any significant increase in relational problems and domestic violence in their family life due to the lockdown. The findings of this study also show that their families acted as an effective psychosocial support system for the participants that help them to cope better with the new challenges:

P10 (Male, 26): My relationship with my wife is good. She is happy that I am at home with her. She is aware that I don't want to be unemployed, but I can't find any job.

P12 (Male, 35): Our relations at home are still good. The lockdown didn't affect our relationship negatively.

According to relational sociological viewpoint, like adults, children are also regarded to be actively engaged in the daily construction of their own and other people's everyday life as social actors, and the family is seen as a system of relations, linking to each other as the husband/father, the wife/mother, and their children, all of which can be conceived as interdependent positions within the structured network of relations (Porpora, 1998, p. 343). Every position needs the other position to exist, such as the parent position is dependent on the existence of the child position and therefore, a change of action in one position causes a change in the other position (Alanen, 2011). Therefore, a new situation in a relationship can affect other relationships as well (Azarian, 2005, p. 52). The findings of our study also support this relational view in the way that increased engagement of fathers in the daily activities of the family has affected the other family members in terms of strengthened parental and spousal ties:

P2 (Female, 22): Although my husband is much more at home now, we don't have an argument or problem. The children are happier now because their father is spending more time with them.

P3 (Female, 24): We are getting along well with my husband during the lockdown. I am happy that he is spending more time at home. He is helping me more with the kids.

As it is stated previously, one of the common economic impacts of the COVID19 pandemic on Syrian families was the significant decrease in family income which led the children to take a more active role in economic activities due to the job loss or lay off that adult breadwinners of the family have experienced. These changes in economic activities may result in a transformation in the traditional division of labor within the family and parent-child and wife-husband relationship. In the case of the Syrian families that participated in our study, even though the economic activities in the family have changed in a way to undermine the dominant breadwinner position of the father, emotional closeness and solidarity still hold a central position in familial relations.

Despite these positive relational impacts of the lockdown on familial relations, the increased time family members spend together due to the economic and social measures may result in the distortion of the usual boundaries making it difficult to set a balance between the social and educational needs of children. Also, for the socio-economically disadvantaged groups such as migrants, closure of schools and continuation of education via distance learning due to the social isolation measures may result in the loss of equality in educational opportunities. Syrian families mostly live in crowded houses with poor conditions and they mostly lack technological 
equipment to follow online education programs (Kazanc1, 2020). The lack of access to technological devices and internet connection is one of the main problems the migrant families face and almost half of the refugee children $(48 \%)$ cannot access distance learning due to the lack of access to technological devices such as television or computer (ASAM, 2020). Although the Turkish government tries to take some particular measures for migrant children by adding additional language classes to online learning systems, these measures will be ineffective without technological, financial, and educational support for migrant families and taking into consideration specific needs of Syrian children (Kollender \& Nimer, 2020). Our participants also shared their worries on distance learning due to the lack of suitable home conditions and adequate knowledge on how to support their children's education in the lockdown process:

P3 (Female, 24): My eldest child started primary school this year, but the school is closed now. He doesn't listen to me when I tell him to study and goes his own way.

P6 (Female, 35): My three children were going to school before the lockdown. They had to quit the school when the schools were closed. I don't know how they can follow the courses from T.V. I don't understand their lessons and I have a small baby to take care of.

The social and educational demands of children increased by the pandemic put the parents, especially the mothers, under pressure of performing as an entertainer and educator. Although some female participants in our study declare that they got more help from their husbands in domestic chore and child care routines during the lockdown, it is still not easy for them to effectively handle these educational challenges. Because of their socio-economically disadvantaged position, these families experience educational challenges in accessing remote education due to the language barrier, lack of technological equipment, and absence of internet or TV connection but they also lack technological and psychosocial guidance that may help them to better compensate for the social and educational needs of their children.

\section{Conclusion}

According to the relational sociological perspective, individuals do not enter into relations with their fixed attributes and identities (Emirbayer \& Mische, 1998). Identities are shaped by social relations and alter as the relations change (Néray, 2016). Uncertainties and difficulties of adaptation to a new and unexpected situation require identities to apply various maneuvers and strategies, and this means an increased agency to regain control in social relations. Social relations are dynamic structures that arise from the interaction processes of social actors, and as a result they require being active and continuous rather than mechanical and stable (Azarian, 2005: 60). In this respect, relational sociological view states that social roles, relations, and identities do not remain constant and invariant as they are. Identities emerge from control efforts in the midst of uncertainties and controversies (White, 2008, p. 1). Control is an integral part of every relationship and control seeking is a response to unstable and unexpected character of social relations (Azarian, 2005, p. 75). 
Before the COVID-19 pandemic, the lives of Syrians in Turkey were subject to various economic and psychosocial stressors due to problems such as language barrier, limited access to social services, perceived discrimination, uncertainties about the future, and lack of livelihood options (Doctors of the World-Turkey, 2020). Due to restriction measures on social and economic life, the COVID-19 pandemic has worsened the effects of the stressors in their lives and has made them look for new coping strategies to control these increased stressors. In this study, the impacts of COVID-19 lockdown on familial, economic, and social lives of Syrian migrants living in Mersin province of Turkey are examined through a relational sociological perspective. It is also aimed to explore the relational strategies and maneuvers used by the Syrian migrants to take control and mitigate the impacts of the COVID-19 lockdown process.

The findings of the study have been discussed under three headings which were derived from the main themes that emerged from the data as social, economic, and familial changes and uncertainties. In the study, the COVID-19 lockdown process is defined as a contingency situation, which is an uncertainty situation arising from unexpected external influences on the social network in which identities try to regain control by implementing various strategies and maneuvers (White et al., 2013, p. 140). The COVID-19, which has been announced by the World Health Organization as of 12 March 2020 as a pandemic, has been a physical, psychosocial, and economic threat for many countries in the world (Relief International, 2020). It continues to bring new risks and uncertainties day by day, especially for the vulnerable groups such as migrants who often struggle with poverty, underpaid working conditions in informal sectors, poor nutrition, and health problems. As well as being a global health crisis, the COVID-19 pandemic is also a contingency situation with its multi-sided psychosocial and economic impacts which were not foreseeable and expected at the beginning to be of this severity.

One of the most drastic impacts of the COVID-19 lockdown was on economic activities. Most of the Syrian migrants in our study stated that working members of their families have experienced a job loss or lay off due to the lockdown and this change in economic relations has triggered an uncertainty and anxiety situation in the family. This finding is consistent with other studies revealing that the Syrian families in Turkey have encountered problems to reach food and hygiene products and experienced difficulties to pay for their rent, bills, and other compulsory expenditures during the lockdown process (ASAM, 2020, Turkish Red Crescent, 2020). Due to the fact that the Syrian migrants mostly work in informal sectors with low wages, temporary suspension and slowdown of economic activities in many sectors led them to experience severe financial damage. From a relational sociological viewpoint, this uncertainty experienced by Syrian migrants due to the economic impacts of the lockdown can be regarded as an increase in ambage which is defined by White (2013, p. 138) as the uncertainty experienced in social roles and role requirements. The economic impacts of the lockdown process on the Syrian migrants' lives led to the suspension or uncertainty of current roles and responsibilities. The findings of the study also show that the drastic change in the economic conditions of the migrant families led them to adopt new strategies and coping mechanisms to take control of this uncertainty situation, which function as a life saver to increase the 
chance of their survival during the pandemic process. Some participants unwillingly assigned their breadwinner role to other members of the family because of the suspension or loss of their job. In some families, even very young children had to start working in risky and unsuitable economic activities for their developmental stages in the pandemic.

During the COVID-9 lockdown, another change and uncertainty process has been experienced in social relations and networks. The accepted norms of social relations have changed in the way that avoiding social and physical contact with neighbors, relatives, and other community members has become a desired norm which is normally the opposite of the socio-cultural greeting norms involving hugs, handshakes, and kissing on the cheek or one's hand. These changes resulted in increased ambiguity which is the uncertainty experienced in meanings, values, and rules that arise in the socio-cultural framework (White, 2013, p. 138). For economically disadvantaged groups such as the migrant participants in the study, using virtual technologies to be in touch with social networks in the pandemic is costly while they have hardship to meet their basic needs. They mostly have to rely upon the family to compensate for their relational needs.

COVID-19 lockdown is also a struggle for most of the individuals because they have to be away from the sources of social support when they need more social support than ever before. Also the uncertainty and unpredictability of the lockdown process make it harder to tolerate these social changes. The Syrian migrants in our study stated that they were very careful in complying with social isolation measures and their social relations had been very limited during the lockdown. Despite this limited social and physical contact, there has been an increased agency in their lives in terms of a strengthened solidarity network within relatives. Borrowing money from relatives appears as a common relational strategy of the Syrian migrants in our study to cope with the economic impacts of the lockdown. This relational strategy is a good example to understand the linkage between context and agency in the way that agency as inseparable from the unfolding dynamics of situations and their problematic features, and agency involves different ways of acting in certain context (Néray, 2016). In the absence of an uncertainty and contingency situation like the COVID-19 pandemic, actors can act more at iterational level of agency, in the way that they can preserve their past patterns of thought and action to sustain stability and order in their lives. With the changes and uncertainties that have arised with the pandemic, the participants of the study had to perform much more in practicalevaluative level of agency to take control of their lives by complying with the social isolation measures, adapting to the new social norms, changing their financial strategies, and strengthening the network of solidarity within the family and with their relatives. These findings are also consistent with the studies revealing that in times of crisis the marginalized and neglected groups such as migrants often use the coping strategy of receiving economic and social support from social networks based primarily on kinship, shared nationality, language, religion, and a sense of collective commitment (Hilfinger Messias et al., 2012; Sacchetto \& Vianello, 2015).

As a result of social isolation measures, suspension of economic activities, and closure of schools, family and family relations become the main source of coping with the increased challenges and uncertainties due to the pandemic. Centralization 
of the family also leads to a change in relational roles and strategies within the family. With regard to the impact of the COVID-19 pandemic on familial life of the Syrian migrants, the findings of the study show that changes in economic activities of the family lead to a change in relational aspects of the family, but instead of a harsh competition, family members have developed effective strategies and maneuvers that result in strengthened family ties.

According to the relational view, the family is seen as a field of interactions that is affected not only by economic relations but also from physical, socio-cultural, and symbolic power relations (Alanen, 2011). This multi-sided understanding of the family as a dynamic social body can be helpful to understand why the changes in economic activities of the family result in strengthened family ties instead of negative relational outcomes. The participants of this study seem to benefit from the lockdown process to build stronger relationships and solidarity within the family. The husbands have started to spend more time with children and become more helpful with household chores. The participants also stated that children have been happier due to their fathers' spending more time with them and their spousal relationships have not been negatively affected by the lockdown. Sharing housework as a family, cooking together, watching a movie, and being in solidarity against the risk of virus can help to build stronger ties in the family and improve family relations (Coyne et al., 2020).

Beside these positive outcomes in familial relations, the lockdown process has been challenging for some families in terms of meeting the social and educational needs of children who were away from formal education due to the closure of schools. Children who have been out of school were also away from social and sportive activities. For most parents, this means a new challenge of trying to keep children busy and safe at home while managing children's educational and childcare needs (Cluver et al., 2020; Connell \& Strambler, 2020). The increased roles of adults, especially of mothers, as an entertainer and educator increased the physical and emotional burden in the family. For those living in low-income and crowded households, these familial changes may be more challenging and stressful combined with the economic impact of the crisis (Cluver et al,. 2020). Also, meeting the educational needs of the children in the distance learning process with a lack of access to technological devices and internet connection is another challenge that the migrant families face in the COVID-19 lockdown. The studies show that the existing measures taken to offer an effective distance learning process do not cover the technological, financial, and educational needs of migrant families (Kollender \& Nimer, 2020; ASAM, 2020). In line with these studies, the Syrian migrants in our study who have children going to school, continuation of education via distance learning have become a challenge because they do not have suitable home conditions and adequate knowledge on how to meet educational needs of their children in the lockdown process.

The findings of our study show that the Syrian migrants who are under temporary protection in Turkey are affected in many aspects from the COVID-19 lockdown, whereas the consequences of its economic impact are much more severe. Most of the Syrian migrants mandatorily quit working or have had to continue to work in unsafe conditions with a high risk of contamination during the lockdowns. Although 
they try to control this contingency process by strengthening the network of solidarity within relatives and greater participation of non-working family members in the workforce to mitigate the economic impacts of the COVID-19 outbreak, these strategies will not be adequate and sustainable if the lockdown process is prolonged. Considering the fact that the lockdown measures can be tightened again at any time with respect to the increase in the spread of the disease, social and economic policies should be expanded to include the Syrian migrants. Also educational policies during the COVID-19 pandemic should include specific measures such as technological support and guidance to mitigate the risks and disadvantages that Syrian children experience in terms of distance learning. The educational challenges they face due to language barrier and insufficient economic and technological resources may lead to termination of schooling and increase the risk of adding new members to the unskilled Syrian workforce.

Although the lockdown measures have been eased with widespread vaccination, the uncertain and dynamic nature of the pandemic still leads to uncertainties about the future. Also, the multi-sided and interlinked psychosocial and economic outcomes of the lockdown period may create long-term effects on Syrian migrants' lives. In this respect, there is a need for further research to identify current and possible long-term psychosocial and economic impacts of the lockdown process on the Syrian population in Turkey. Although this study is an initial attempt to present the multi-sided changes and challenges Syrian families face during the pandemic, further studies with extended participant groups may reveal the changing roles and responsibilities of family members who are in different ages and life stages such as single, married, elderly, or adolescent. Also, considering that Syrian migrant families with different socio-economic status can have different experiences and coping strategies regarding the economic, social, educational, and familial challenges, carrying out additional research representing various migrant populations will be helpful to define the situation more comprehensively.

\section{Declarations}

Competing Interests The author declares no competing interests.

\section{References}

Alanen, L. (2011). Moving towards a relational sociology of childhood. In: Braches-Chyrek, R, Röhner, C, Schaarschuch, A, Sünker, H (eds) Kindheiten. gesellschaften - interdisziplinäre zugänge zur kindheitsforschung, p. 21-44. Opladen: Barbara Budrich Verlag.

Association For Solidarity With Asylum Seekers and Migrants (ASAM) (2020). COVID-19 salgınının Türkiye'de mülteciler üzerindeki etkilerinin sektörel analizi. Retrieved from https://data2.unhcr.org/ en/documents/download/76640

Association For Solidarity With Asylum Seekers and Migrants (ASAM) (2021). A systematic review of reports on the impact of COVID-19 on refugees- II. Retrieved from http://sgdd.org.tr/yayinlar/ 2021/akademi/asam_academy_review_reports_impact_covid19_onrefugees_ii.pdf?trk=organizati on-update_share-update_update-text 
Azarian, G. R. (2005). The general sociology of Harrison White: Chaos and order in networks. Palgrave-Macmillan.

Braun, V., \& Clarke, V. (2006). Using thematic analysis in psychology. Qualitative Research in Psychology, 3(2), 77-101. https://doi.org/10.1234/12345678

Cluver, L., Lachman, J. M., Sherr, L., Wessels, I., Krug, E., Rakotomalala, S., et al. (2020). Parenting in a time of COVID-19. The Lancet. https://doi.org/10.1016/S0140-6736(20)30736-4

Connell, C.M. \& Strambler, M. (2020). Studying the unintended consequences of COVID-19 responses on family wellbeing and child safety. Retrieved from https://medicine.yale.edu/psychiatry/news-artic le/24306/

Coyne, L. W., Gould, E. R., Grimaldi, M., Wilson, K. G., Baffuto, G. \& Biglan, A. (2020). First things first: Parent psychological flexibility and self-compassion during Covid-19. Behavior Analysis in Practice. https://doi.org/10.1007/s40617-020-004-35-w

Crabtree, B. F., \& Miller, W. L. (1992). Doing qualitative research: Research methods for primary care (Vol. 3). Sage.

Creswell, J. W. (2013). Qualitative inquiry and research design: Choosing among five approaches (3rd ed.). Sage.

Directorate General of Migration Management (2021). Yıllara göre geçici koruma kapsamındaki Suriyeliler. Retrieved from https://www.goc.gov.tr/gecici-koruma5638

Doctors of the World- Turkey (2020). Psychosocial effects of COVID-19 in the framework of MHPSS needs of Syrian refugees in Turkey April-May 2020. Retrieved from https://www.dunyadoktorlari. org.tr/medya/yayinlar/psycho-social-effects-of-covid-19-in-the-framework-of-mhpss-needs-of-syrian-refugees-in-turkey

Emirbayer, M., \& Mische, A. (1998). What is agency? American Journal of Sociology, 103, 962-1023.

Fegert, J. M., Vitiello, B., Plener, P. L., \& Clemens, V. (2020). Challenges and burden of the coronavirus 2019 (COVID-19) pandemic for child and adolescent mental health: A narrative review to highlight clinical and research needs in the acute phase and the long return to normality. Child and Adolescent Psychiatry and Mental Health, 14, 20. https://doi.org/10.1186/s13034-020-00329-3

Guadagno, L. (2020). Migrants and COVID-19 pandemic: An initial analysis. Retrieved from https://relie fweb.int/sites/reliefweb.int/files/resources/mrs-60.pdf

Hilfinger Messias, D. K., Barrington, C., \& Lacy, E. (2012). Latino social network dynamics and the Hurricane Katrina disaster. Disasters, 36(1), 101-121. https://doi.org/10.1111/j.1467-7717.2011. 01243.x

Holmes, E. A., O'Connor, R. C., Perry, V. H., Tracey, I., Wessely, S., Arseneault, L., et al. (2020). Multidisciplinary research priorities for COVID-19 pandemic: A call for action for mental health science. The Lancet Psychiatry., 7(6), 547-560.

Ikizer, G., Karanci, A. N., Gul, E., \& Dilekler, E. (2021). Posttraumatic stress, growth, and depreciation during COVID-19 pandemic: Evidence from Turkey. European Journal of Psychotraumatology, 12(1), 1872966. https://doi.org/10.1080/20008198.2021.1872966

Kara, E. (2020). KOVID-19 pandemisindeki dezavantajlı gruplar ve sosyal hizmet işgücünün işlevi. Türkiye Sosyal Hizmet Araştırmaları Dergisi, 4(1), 28-34.

Kasapoglu, A., \& Akbal, A. (2020). Relational sociological analysis of uncertainties: The case of Covid19 in Turkey. Advances in Social Sciences Research Journal, 7(4), 197-228. https://doi.org/10. 14738/assrj.74.8116

Kazanc1, H. (2020). Syrian refugees hit harder amid Covid-19: Expert. Retrieved from https://www.aa. com.tr/en/latest-on-coronavirus-outbreak/syrian-refugees-hit-harder-amid-COVID-19-expert/18825 14

Kirişçi, K. \& Erdoğan, M. (2020a). Turkey and COVID-19: Don’t forget refugees. Retrieved from http:// foreignpolicy.org.tr/turkey-and-COVID-19-dont-forget-refugees/

Kirişçi, K. \& Yavcan, B. (2020b). As COVID-19 worsens precarity for refugees, Turkey and EU must work together. Retrieved from https://www.brookings.edu/blog/order-from-chaos/2020/06/11/asCOVID-19-worsens-precarity-for-refugees-turkey-and-the-eu-must-work-together/

Kollender, E. \& Nimer, M. (2020). Long-term exclusionary effects of Covid-19 for refugee children in the German and Turkish education systems: A comparative perspective . Istanbul Policy Center.

Köngeter, S. \& Smith, W. (2014). Transnational agency and migration. Actors, movements and social support. London: Routledge.

Kumar, K., Mehra, A., Sahoo, S., Nehra, R., \& Grover, S. (2020). The psychological impact of COVID19 pandemic and lockdown on the migrant workers: A cross-sectional survey. Asian Journal of Psychiatry, 53, 102252. https://doi.org/10.1016/j.ajp.2020.102252 
Lechner, E. (2014). Biographical research among immigrants in Portugal: Collaborative research and the analytical relevance of personal accounts. História (são Paulo), 33(1), 97-108.

Liem, A., Wang, C., Wariyanti, Y., Latkin, C.A. \& Hall, B.J. (2020). The neglected health of international migrant workers in COVID-19 epidemic. The Lancet, 7(4) :e20.

Lombardo, C., Mauceri S. (2020), La società catastrofica. Vita e relazioni sociali ai tempi dell'emergenza COVID-19, Franco Angeli, Milano.

McAuliffe, M. \& Bauloz, C. (2020). The coronavirus pandemic could be devastating for the world's migrants. Retrived from https://www.weforum.org/agenda/2020/04/the-coronavirus-pandemiccould-be-devastating-for-the-worlds-refugees/

Mische, A. (2011). Relational sociology, culture, and agency. In J. Scott \& P. Carrington (Eds.), The Sage handbook of social network analysis (pp. 80-97). Sage Publications.

Musolino, S. (2020). Families, relational scenarios and emotions in the time of COVID-19 Pandemic. Italian Sociological Review, 10(3S), 737-751.

Néray, B. (2016). The relational approach in sociology: A study of dependence. Review of Sociology, 26(4), 5-28.

Porpora, D. V. (1998). Four concepts of social structure. In M. Archer, R. Bhaskar, A. Collier, T. Lawson, \& A. Norrie (Eds.), Critical realism: Essential readings (pp. 339-355). Routledge.

Relief International (2020). Impact of COVID-19 outbreak on Syrian refugees in Turkey. Retrieved from https://reliefweb.int/sites/reliefweb.int/files/resources/76504.pdf

Rolland, J. S. (2020). COVID-19 pandemic: Applying a multisystemic lens. Family Process, 59(3), 922-936.

Sacchetto, D., \& Vianello, F. (2015). Unemployed migrants coping with the economic crisis: Romanians and Moroccans in Italy. Jounal of International Migration and Integration, 17, 839-852.

Tang, S. \& Li, X. (2021). Responding to the pandemic as a family unit: Social impacts of COVID-19 on rural migrants in China and their coping strategies. Humanities and Social Sciences Communications, 8. https://doi.org/10.1057/s41599-020-00686-6

Tekin Babuç, Z. (2016). Suriyeli aileler ve eşikteki yaşamları: Mersin örneği. In A. Kasapoğlu (Ed.), Uygulamall İlişkisel Sosyoloji (pp. 216-233). Yeni İnsan Yayınevi.

Tekin Babuç, Z. (2018). Mersin ilindeki Suriyeli çocukların aile ve sosyal ilişkilerinde yaşadıkları ambivalansın ilişkisel sosyolojik bir analizi. Sosyoloji Araştırmaları Dergisi, 21(2), 317-355. https://doi.org/10.18490/sosars.476192

Turkish Red Crescent (2020). Impact of COVID-19 on refugee populations benefitting from the emergency social safety net (ESSN) programme. Retrieved from https://media.ifrc.org/ifrc/wp-content/ uploads/sites/5/2020/05/Impact-of-COVID-19-on-Refugee-Populations-Benefitting-from-ESSNProgramme.pdf

UNHCR (2018). Turkey operational highlights 2018. Retrieved from https://www.unhcr.org/tr/wp-conte nt/uploads/sites/14/2019/02/UNHCR-Turkey-Operational-Highlights-2018-Final.pdf

Usher, K., Bhullar, N., \& Jackson, D. (2020). Life in the pandemic: Social isolation and mental health. Journal of Clinical Nursing. https://doi.org/10.1111/jocn.15290

White, H. (2008). Identity and control: How social formations emerge. 2nd (rev). Princeton University Press.

White, H., Godart, F., \& Thiemann, M. (2013). Turning points and the space of possibles: A relational perspective on the different forms of uncertainty. In F. Depelteau \& C. Powell (Eds.), Relational sociology: From project to paradigm (Vol. 1, pp. 137-154). Palgrave.

World Food Programme. (2020). COVID-19 pandemic in Turkey: An assessment of readiness and impact on refugees living in-camps. WFP Turkey Country Office. Retrieved from https://www.wfp. org/publications/august-2020-covid-19-pandemic-turkey-assessment-readiness-and-impact-refug ees-living

Publisher's Note Springer Nature remains neutral with regard to jurisdictional claims in published maps and institutional affiliations. 